\title{
Development of Outcome Assessments at WPI
}

\author{
William W.Durgin \\ Lance Schachterle \\ Worcester Polytechnic Institute \\ Worcester, MA 01609
}

\begin{abstract}
The WPI PLAN, adopted by the WPI faculty in 1970, strongly anticipates current thinking about student outcomes assessments by structuring degree requirements that mandate that students demonstrate their ability to perform professional functions embodied in ABET Criteria 2000, especially Criteria 3 and 4. The WPI faculty has also practiced both student and self evaluations of these outcomes through respectively grades and peer review (both departmental and campuswide) of student performance.
\end{abstract}

\section{Introduction}

The WPI PLAN, a project-based curriculum developed over the past 25 years, includes degree requirements which are, themselves, assessment measures. Based on the mission of the Institute, faculty developed detailed educational objectives and created a curriculum based on those objectives. Furthermore, the faculty created a system of ongoing evaluation that demonstrates the achievement of these objectives and uses the results to improve the effectiveness of the program.

It may be useful to other institutions for us to review the process by which WPI's assessment measures were designed and adopted. Clearly, attaining wide acceptance within the community for the assessment measures is crucial, yet it is also clear that such acceptance will not be unanimous. Equally important is supporting faculty-wide ongoing review and evolution of assessment measures, as we shall illustrate.

Since assessment measures must be closely associated with desired outcomes, the outcomes must be stated. In 1987, the WPI faculty endorsed the following goals for our undergraduate program: "to lead students to develop an excellent grasp of fundamental concepts in their principal areas of study; to lay a foundation for life-long renewal of knowledge; to gain a mature understanding of themselves; and, most importantly, to form a deep appreciation of the interrelationships among basic knowledge, technological advance, and human need. These principles are today manifest in the WPI PLAN, a unique, project-based program which emphasizes intensive learning experiences and direct application of knowledge."

\section{WPI Projects \& Outcomes Assessment}

The degree requirements that principally constitute the project-based outcomes assessments are three in number:

The Humanities "Sufficiency " Project, which measures whether the student has achieved a sufficient background in a self-selected area of the Humanities or Arts to be likely to continue lifelong learning in that area;

The "Interactive Qualifying Project" (or IQP) which assesses the capacity of students to reflect on the impacts of science and/or technology on societal values and structures; and

The "Major Qualifying Project" (or MQP) which measures the ability of students to begin working on open-ended professional problems at the level assumed of someone beginning professional practice or graduate school.

Collectively, WPI believes these three projects provide students with a learning environment where they have rich opportunities to achieve the goals the faculty articulated in 1987. In addition, these projects also promote the outcomes proposed by the new "ABET Criteria 2000," specifically as follows:

"Engineering programs must demonstrate that their graduates have: 
a) an ability to apply knowledge of mathematics, science and engineering;

b) an ability to design and conduct experiments, as well

as to analyze and interpret data;

c) an ability to design a system, component or process to meet desired needs;

d) an ability to function on multi-disciplinary teams;

e) an ability to identify, formulate, and solve engineering problems;

f) an understanding of professional and ethical responsibility;

g) an ability to communicate effectively;

h) the broad education necessary to understand the impact of engineering solutions in a global/societal context;

i) a recognition of the need for and an ability to engage in life-long learning;

j) a knowledge of contemporary issues; and

k) an ability to use the techniques, skills and modern engineering tools necessary for engineering practice."

We will now review each degree requirement and how the faculty assess it.

First, the Humanities "Sufficiency" project. The WPI faculty believe strongly that every student should attain substantive understanding of the humanities through study in a sequence of thematically related courses and project work. The experience was designed to allow students to acquire an understanding of how knowledge is obtained and expressed in a non-technical area. Students, with the support of advisors, select five courses where they must define a thematic or intellectual relationship--for example, five courses dealing with aspects of history of science, or theater production, or creative writing. They conclude their sequence of study by writing, with a single faculty advisor, a final project wherein they conduct independent study and a critical or research essay (or original work or performance).

In this example, the outcome---substantive understanding of the humanities--- was first agreed upon by the faculty. This outcome grew from frustration with typical humanities distributions common in technical education. The process by which the outcome was to be achieved could then be designed, as a five course sequence with the independent project conducted as the sixth element. However, this is by no means the only avenue by which the outcome may be achieved. The assessment measure is the final critical or research essay. Students are free to choose such advisors who, typically, develop areas in which they specialize.
Faculty assess the student achievement initially by reviewing the thematic coherence of the proposed sequence of courses, and then advising the student's final essay or production. In turn, the faculty benchmark their function as advisors by peer reviews of completed essays, which assess how well crucial goals like communications skills, articulating a clear and convincing argument, and showing a level of interest which promises to lead to lifelong learning are achieved by the final essay (ABET Criteria b, f, g, h, i, and $j$ above). Finally, the final essays are available as open literature for review by anyone in the community.

Another of the WPI degree requirements, the Interactive Qualifying Project, resulted from faculty concern that students needed to develop appreciation of the inter-relationships of science, technology and society. The objective of the IQP is to enable graduates to understand, as citizens and professionals, how their careers will affect the larger society of which they are part. This project is the equivalent of three courses and is typically conducted in a small team setting under the guidance of one or more faculty advisors. Any faculty member can advise any undergraduate(s) in this project activity. As such, faculty, as a whole, clearly have ownership of the IQP and have developed an expectation that everyone ought to participate.

Interactive Qualifying Projects by definition are set in a societal context and are frequently pre-arranged with other organizations such as government agencies, museums, societies, and foundations. Students are expected to prepare a proposal, conduct background research, conduct the study, and prepare a written report. The faculty advisor works with the project team throughout the project, finally reading and evaluating the report. Thus, the report itself is the outcome reflecting achievement of understanding of the inter-relationship of technology and society in an instance, that usually has broad implications.

The three courses equivalence for the IQP is, in fact, one of the principal reasons WPI adopted a seven week term basis for the academic schedule. Normally, students take three courses per term but clearly can pursue the entire IQP in one seven-week term which provides opportunity for off-campus project centers. Approximately one-third of WPI undergraduates take advantage of this opportunity to conduct their IQP's at established residential project centers in Washington, DC, San Francisco, Bangkok, London, Venice, Puerto Rico and Costa Rico. 
Assessment of progress on IQP's occurs during weekly meetings of the working team, which may include students, one or more faculty, and one or more liaisons from organizations sponsoring the project. Students in multi-term projects receive formative grades each term, as well as a final summative grade (which counts towards WPI Honors.) Faculty peer review completed IQP's biennially, to measure how successfully the final reports articulate student outcomes in important institutional goals such as "forming a deep appreciation of the interrelationships among basic knowledge, technological advance, and human need" (from the WPI Goals), and ABET Criteria $\mathrm{c}, \mathrm{d}, \mathrm{f}, \mathrm{g}, \mathrm{h}, \mathrm{i}$ and $\mathrm{j}$ above.

The final project-based degree requirement is the Major Qualifying Project (MQP). Our faculty wanted to be sure that students demonstrate, in their major field of study, the application of the skills, methods, and knowledge of the discipline to the solution of a problem that would be representative of the type to be encountered at the beginning of one's career. Typically, small teams are formed to focus the project work on a topic offered by industry, the faculty, or the students themselves. Again, the course equivalence is three courses but usually spread throughout the year. Both the advisor and students must be in the same discipline, although multi-disciplinary teams are frequently formed together with an advising group of faculty from the represented disciplines.

Students prepare a proposal delineating what, why, where, when, and how they will conduct the project. Frequently, MQP's involve engineering design so that specifications must be developed, the design conducted, and demonstration of achievement must be made. In this case, oral presentations are necessary in the weekly team meetings and, often, at the project conclusion. The report, itself, is one of the outcomes reflecting the objective. Additionally, written and oral communications are demonstrated as are other desired elements such as teamwork. Thus the MQP provides assessment on virtually all of the ABET Criterion 3, as well as WPI's own specific goals.

To begin familiarizing students with professional expectations for reporting results of technical work in formal oral sessions, near the end of every year WPI schedules a "Project Presentation Day" where seniors (students normally wait to the final year to tackle the MQP) present their results to audiences consisting of faculty, other students (especially juniors contemplating the start of their own MQP's) and increasingly, professionals from industries which sponsor MQP's on campus. These presentations are organized within each department, and emulate professional conferences with multiple sessions, formal chairs and time keeping--and tough questions from the audience about "why didn't you think of...."

As with the Interactive Qualifying Projects, the Major Qualifying Projects are peer reviewed by faculty on a biennial periodicity. Feedback is thus provided to individual faculty advisors such that quality is maintained and improved. A sample of the most recent peer review for the MQP is attached as Appendix A.

\section{Conclusion}

The key to adoption of these assessment measures was, first, the faculty recognition of objectives and, second, the development of a curriculum which achieved the outcomes. Clearly, faculty must have ownership of both the objectives and the curriculum. Once these elements are in place, the faculty must establish operational goals regarding specific expectations associated with the completion of these projects. Once such metrics are established, feeding the results of assessing both student and faculty performance (respectively, student grades and faculty peer reviews) back into continuous improvement of the whole program can become part of institutional culture.

\section{Appendix A -- Recommendations Made to the Faculty as a Result of the Last MQP Peer Review (1995)}

- Student project advisor evaluations indicate that students want the advisor to discuss expectations for performance and for grading, early in the project.

- Students and faculty should review faculty policy on team projects, as stated in "Group Qualifying Project Efforts" (p. 29 in the current Catalog) for guidelines of an "authorship page" specifying levels of contribution in all team-written reports.

- Pressures on faculty time make advising MQP's in groups of three more desirable than ever, in addition to providing opportunities for students to learn how to work successfully on teams.

- Faculty should review and use as needed the information in the packet on the WPI Projects Program, which includes an overview (aimed at potential sponsors) as well as sample legal documents. 
- While significant progress has been made in providing all MQP students with an opportunity to present their results orally, not every department specifically requires and schedules MQP oral presentations for every student. This practice is strongly encouraged.

- Word processing has assisted in improving basic levels of writing and revising, but many reviewers observed projects which did not fully demonstrate the critical thinking and writing skills increasingly important for students to succeed in tight job markets.

- Virtually every department looked with some care at grade distributions, which were self-reported as ranging from $88 \%$ A's to $58 \%$ A's. Some reviewers (not all) found their own analysis of grade distributions matched those awarded by the project advisors; others feared grade inflation was still at work, despite a clear facultyvoted policy on what the WPI grades $\mathrm{A}, \mathrm{B}$, and $\mathrm{C}$ mean (1996-97 Catalog, p. 169.) 